\title{
PENSANDO UMA DRAMATURGIA DE GRUPO ${ }^{1}$
}

André Carreira

André Felipe Costa Silva

RESUMO: O presente artigo versa sobre os procedimentos de criação coletiva de dramaturgia dentro de grupos teatrais brasileiros estáveis. A reflexão provém de um confronto entre a estrutura da dramaturgia que nasce literatura, paralela à criação de todas as partes que compõem um espetáculo, e daquela que se define como elemento inseparável da encenação - uma discussão sobre a novidade do que desenvolvem os "criadores coletivos": desenvolvem uma realmente nova dramaturgia? Falam de um mesmo ou de um outro teatro?

PALAVRAS-CHAVE: dramaturgia, criação coletiva, teatro de grupo, grupos de São Paulo.

Definir o lugar e a função do texto dentro da realização cênica é uma difícil tarefa nas reflexões que tangem a dramaturgia. Além de uma definição estética, nos deparamos com a infindável querela ideológica: em que mãos cairá o poder de tomar decisões centrais do trabalho? É complexo falar hoje sobre questões de autoria, ainda mais quando falamos em grupo, em teatro de grupo, contexto no qual a noção de funções e assinaturas é bastante diversificada, passeando entre os sítios do indivíduo e do coletivo.

Durante um longo período o autor de um espetáculo teatral era o dramaturgo, o texto era visto como aquilo que precedia e determinava a encenação. A dramaturgia clássica, seguindo os preceitos aristotélicos, era estruturada de tal forma a ser transposta à cena, como um sistema formal e autônomo. Desde Aristóteles até as renovações teatrais propostas ao final do século XIX, com raras exceções como manifestações populares como a Commedia dell'arte, o texto dramático era o regente da encenação. A idéia de autoria teatral, portanto, estava ligada somente ao dramaturgo.

Desse modo, por muito tempo defendeu-se a soberania do texto sobre a realização cênica, estabelecendo-se a chamada cultura textocentrica. É na primeira metade do século XX que definitivamente se reconhece a figura do diretor como o responsável

${ }^{1}$ Projeto de Pesquisa: Áqis - Núcleo de pesquisa sobre procedimentos de criação artística CEART/UDESC. Coordenação: Prof. Dr. André Carreira. André Felipe Costa Silva, Bolsista de Iniciação Científica, CNPq. 
pela criação e realização da cena, dividindo a autoria do espetáculo com o dramaturgo. Nomes de encenadores como Stanislavski, Copeau e Meyerhold aparecem associados aos de autores como Tchekhov, Gorki, Maiakovski e Strindberg. Naquele momento, a encenação ainda era, em geral, centrada no texto, mas se diferia do procedimento clássico na sua forma de encarar a relação texto-representação.

A tentativa clássica de transposição do texto ao palco foi descoberta como ilusória, os enfoques dentro das redes de sentido que a dramaturgia propõe e as escolhas estético-ideológicas passaram a estar mais intensamente conectadas à função do encenador. É o início da noção da obra aberta, que mais tarde a semiologia irá aprofundar e clarificar. Ainda assim, as tentativas que marcaram o surgimento do teatro moderno tinham o texto como fonte e destino do espetáculo e, portanto, a idéia textocentrica manteve-se como pilar estruturante de muitas das vanguardas teatrais (com algumas exceções em trabalhos como os de Meyerhold, Craig e Artaud).

Esta idéia da utilização do texto como pré-texto reconfigura a dramaturgia em sua função, garantindo maior liberdade de interpretação ao encenador e, posteriormente, ao grupo - uma idéia que de forma nenhuma é ultrapassada pelos procedimentos que virão a seguir no âmbito da dramaturgia. Outra inovação no trato da escritura cênica, que surgiu em meados do século XX, foi a fusão das funções de diretor e dramaturgo. Dramaturgos encenavam suas próprias peças, fazendo inseparável a criação do texto e da encenação. Um exemplo claro dessa união foi o desempenho de Bertolt Brecht nas montagens do Berliner Ensemble. De acordo com Bernard Dort, para Brecht, escrever uma peça e encená-la faziam parte de um único e mesmo ato (DORT, 1977, p. 63).

Nas décadas de 60 e 70, entretanto, adjacente aos movimentos de contracultura, questionava-se a autoridade do diretor junto ao dramaturgo e se fortalecia a figura do ator e da coletividade do grupo. Por conseguinte, quebraram-se padrões e formas tradicionais, o texto já não era elemento fundamental para a realização cênica, as funções de desempenho dentro do grupo se dissolveram ainda mais.

De um lado o teatro-laboratório de Grotowski preocupava-se com questões ligadas à intensa pesquisa individual do ator, encontrando um teatro ligado à devoção e ao ritual. De outro, o grupo francês Théâtre du Soleil, guiado por Ariane Mnouchkine, encontrava na improvisação a possibilidade da escrita coletiva. Enquanto grupos como o Living Theatre e encenadores como Tadeuz Kantor, abandonando o texto teatral tradicional, encontravam formas que desafiavam o teatro e dialogavam com novas linguagens como a perfomance e o happening. 
O teatro expandiu suas fronteiras, permitindo novos pontos de contato com as outras artes - circo, dança, artes visuais, etc - gerando inovadoras linguagens e diversas possibilidades criativas. A figura do ator $-\mathrm{o}$ ator propositor, o ator-criador - foi levada ao centro do processo coletivo, se articulando nas mais diferentes tarefas e funções. Não diferente, a autoria dramatúrgica foi compartilhada pelo coletivo, constituindo uma nova forma de enxergar e desenvolver o texto teatral.

Se a dramaturgia tradicional se concentrava na figura solitária do escritor, constituindo um trabalho autônomo e propositivo, que nasceu literatura, paralelo a todas as partes que compõem um espetáculo, nas chamadas criações coletivas a dramaturgia nasce como elemento inseparável da encenação, concebida pelo grupo. Contudo, inevitavelmente a criação de uma dramaturgia coletiva, parafraseando Jean-Jacques Roubine, pressupõe a invenção de um método (ROUBINE, 1982, p. 67).

Uma análise sobre a prática de grupos que trabalham com a criação dramatúrgica coletivizada permite a constatação de diferentes procedimentos de realização dessa tarefa. Muitos dos grupos encarregam uma pessoa de atuar como um mediador entre a cena e o texto, esta pessoa é responsável pela "textualização" da cena, participando e intervindo durante o processo de criação junto ao grupo - essa função é muitas vezes denominada pelo termo alemão dramaturg. Em geral o dramaturg é um escritor convidado pelo grupo que, junto à equipe criadora, pode organizar um texto inédito a partir da criação durante os ensaios ou servir como mediador entre a dramaturgia escolhida e a abordagem do grupo sobre o texto, função que não excluí o escritor profissional dos novos procedimentos.

O processo chamado colaborativo, segundo a visão de alguns grupos, se organiza de maneira distinta ao genérico processo coletivo, tendo cada membro do grupo uma função definida, mas que funciona de modo fluído durante a criação da encenação, a criação é compartilhada. A idéia é de um trabalho horizontal, em que nenhuma das funções se sobrepõe à outra, todos interferem na criação de todos, sem que se negue a responsabilidade por uma área específica. A dramaturgia, portanto, está intrinsecamente inserida nas outras funções, colaborando e recebendo colaborações de toda equipe criadora. Cabe ao dramaturgo ou dramaturg, a tarefa de organizar, cortar e fechar o material textual.

O trabalho de improvisação é também muito comum nas criações dramatúrgicas coletivizadas, baseando-se em pontos de referência de interesse do grupo, como temas, indicações técnicas, proposições de espaço, entre outros. Um grupo que há muito 
desenvolve eficazmente esse procedimento, e por isso serve de referência para tantos outros, é o Théâtre du Soleil. O trabalho do grupo é guiado por uma pesquisa intensa e uma rica coleta de materiais relacionados ao espetáculo em desenvolvimento. A pesquisa do improvisador é enriquecida por essas leituras, experiências práticas e reflexões que o ajudarão na improvisação e, conseqüentemente, na composição das cenas.

Analisando grupos brasileiros estáveis, que trabalham com a criação dramatúrgica coletivizada, podemos perceber a utilização desses procedimentos, cada qual com suas especificidades. O grupo paulistano XIX, surgido em 2001 a partir de um curso de direção coletiva ministrado por Antônio Araújo, trabalha desde a criação de seu primeiro espetáculo, Hysteria, de forma autodenominada colaborativa. As criações do grupo nascem de uma pesquisa contínua da vida privada brasileira, lidando com a memória histórica e afetiva do país e seus cidadãos a partir de temas amplos como "mulher", "casa" e "amor". O primeiro estágio de criação do grupo parte de uma intensa pesquisa e coleta de materiais (cinema, livros, depoimentos) para depois partir para uma etapa teórica e reflexiva e seguidamente à cena. Quanto a esse procedimento, o diretor do grupo Luiz Fernando Marques aponta:

Durante essa pesquisa teórica, algumas coisas chamam a nossa atenção, então a gente acaba desenvolvendo essa escolha, às vezes é o trecho de um texto que a gente leva para a cena [...]. Às vezes o ator traz uma narrativa, aí a gente conversa e transforma essa narrativa em cena dialógica, então não tem uma regra clara. Geralmente tem um ponto de partida que eu proponho, ou um ator ou o diretor de arte. (entrevista com equipe ÁQIS, 2007)

A dramaturgia, desse modo, é construída conjuntamente com a cena, através de proposições previamente estabelecidas pelo grupo e improvisações ou workshops $^{2}$ a partir do material da pesquisa coletiva. Apesar de o grupo trabalhar de modo colaborativo, não existe um membro responsável pela dramaturgia das peças que, diferente das outras funções, fica totalmente a cargo de todo o grupo:

\footnotetext{
${ }^{2} \mathrm{O}$ workshop é outro procedimento freqüente nas criações coletivas, consiste basicamente em um integrante trazer à sala de ensaio uma proposta de cena, que será incorporada ou não à encenação.
} 
[...] na relação de criação existe uma contaminação de cada área e existe um momento final, onde cada um responde por sua área. Como não existe a função do dramaturgo, a dramaturgia acaba ficando nesse campo louco, onde todo mundo pode entrar, onde todo mundo pode sair. É uma loucura, mas também é interessante. (entrevista com equipe ÁQIS, 2007)

No trabalho da Cia. Livre nenhum dos integrantes fixos do grupo se encarrega inteiramente da "textualização" das criações do coletivo, entretanto, diferente do Grupo XIX, a Cia. Livre tem a prática de convidar dramaturgs, que virão a auxiliar nesse processo. A compania paulistana, que existe desde 1999, já teve várias fases, trabalhando desde textos prontos e textos base a textos absolutamente coletivos. Os processos de criação coletivizada de dramaturgia partem na maioria das vezes de um estímulo inicial proposto pela diretora do grupo Cibele Forjaz, engendrando posteriormente pesquisa e discussão teórica, improvisação e workshop, aos moldes de um processo colaborativo, de trocas e contribuições.

O último trabalho, VemVai, contou com a participação, na etapa de pesquisa e précriação, do antropólogo Pedro Cesarino, que ajudou o grupo nas discussões do tema que o projeto propunha, para que depois viesse ao processo o dramaturg Newton Moreno, que organizou textualmente a cenas concebidas na primeira fase. A criação das cenas, como diz Cibele Forjaz, passa pela cabeça e pelo corpo de cada um dos integrantes:

Nós trabalhamos muito em conjunto [no processo do VemVai], criando cenas com base tanto em textos teóricos quanto em mitos. Tivemos vasta discussão sobre esse tema com o antropólogo Pedro Cesarino durante seis meses. E eu não fiquei de fora, todos nós entrávamos em cena para criar juntos, e apresentávamos esse material para o dramaturgo [...]. Então, eu e todos os atores fomos criadores da história e também da encenação, porque quando se cria um espetáculo a partir de cenas improvisadas e workshops, a linguagem está sendo elaborada em conjunto, ao vivo. Em dado momento, cada um foi para o seu lugar: os atores se concentraram naquele texto a partir do momento que já existia texto (escrito pelo Newton), eu saí de cena e olhei de fora... Assim, cada um pôde se dedicar à sua função. Mas nos primeiros oito meses de criação, todo mundo fez tudo. (entrevista com equipe ÁQIS, 2007) 
Já na Cia. do Feijão, também paulistana, o trabalho de dramaturgia assim como o dos dois outros grupos, parte muitas vezes do coletivo, mas a função de dramaturgo ou dramaturg fica na mão dos dois diretores, Pedro Pires e Zé Ernesto Pessoa. No último espetáculo do grupo, Pálido Colosso, diferente dos trabalhos anteriores, o material de criação partiu basicamente da improvisação, de materiais coletados e da memória dos atores, sem um texto de referência, constituindo um verdadeiro trabalho coletivo. Quanto a este trabalho, Zé Ernesto fala:

[...] se pode quase dizer que é uma dramaturgia do grupo, nós temos cada vez mais no horizonte que todo mundo pode fazer tudo. Tem as especializações, por necessidade, mas é um progresso continuado de todo mundo. Nós acabamos amarrando, mas as histórias são deles, nós fazemos enxertos, costuras, mas no teatro de grupo todo mundo acaba tendo que saber tudo, sabe pouco, menos de uma coisa, mais de outra, mas o caminho é uma padronização até hierárquica. (entrevista com equipe ÁQIS, 2007)

O procedimento de criação, portanto, é semelhante aos do Grupo XIX e da Cia. Livre, tendo, todavia, membros do grupo que respondem diretamente pela dramaturgia. Quanto à hierarquia interna do grupo, pretende-se uma relação de horizontalidade, trabalhando colaborativamente, buscando igualdade na diferenciação nas palavras de Pedro Pires: "Todo mundo é igual, com funções diferentes" (entrevista com equipe ÁQIS, 2007).

Voltamos então à questão da autoria dramatúrgica e à procura do local e função do texto teatral: como situar a dramaturgia coletiva? Em seu Dicionário de Teatro, Patrice Pavis distingue na realização cênica a "escritura dramática" e a "escritura cênica" (PAVIS, 2005, p. 131-132). A escritura dramática nada mais é do que o texto literário, o texto dramático, que tradicionalmente orienta a escritura cênica. A escritura cênica é basicamente o conjunto e a interação de sistemas cênicos (texto, representação, espaço), aquilo que constitui a própria encenação.

A criação coletiva de espetáculos, entretanto, tem por prática a construção simultânea das escrituras dramáticas e cênicas, o que impossibilita uma verdadeira distinção das duas instâncias. O texto já não é fechado em si mesmo, não constituindo o caráter de uma obra literária, não possui autonomia sobre a encenação, não é mais do que um instrumento do espetáculo. É, no entanto, cada vez mais freqüente a edição 
destes textos em publicações dos grupos, o que me faz perguntar: qual o sentido da publicação escrita de um texto construído junto à cena? Em que momento ele também ganha valor autônomo?

É evidente que para constituir um valor literário, possibilitando entendimento ao leitor, o texto precisaria receber um trato posterior que não interessa à encenação. É possível analisar esse tipo de escritura dramática de uma encenação quando desvinculada de toda sua realização cênica? Constitui validade apenas como elemento de registro de uma experiência, junto a olhares e impressões do grupo sobre o processo de criação? Roubine, ao falar do Théâtre du Soleil e sua negação em publicar o texto L'âge d'or, considera o texto coletivo elemento inseparável de sua representação e, "por isso mesmo, impublicável” (ROUBINE, p.69, 1982). Enquanto Janaina Leite, atriz do Grupo XIX em prefácio do livro Hysteria/Hygiene, contesta o teórico francês:

[...] "Com todo respeito, monsieur, mas porque é que nós, os 'criadores coletivos', somos impublicáveis?" [...] A idéia de "texto de teatro" que, ainda hoje, define-se por sua autonomia em relação à cena e pela assinatura de um único criador, talvez precise ter seus contornos dilatados para poder abarcar o novo teatro que se vem fazendo, impensável fora do processo que o concebe. Esse novo texto de teatro, fruto de uma nova concepção de autor, exigirá uma leitura vertical. O que quer dizer que não basta seguir a linha horizontal da fábula. É preciso ter em mente que este texto está intimamente ligado a um novo pensamento sobre o fazer teatral. Fazer este que se quer radicalmente coletivo, polifônico, impuro - já que faz uso de todos os textos, dramáticos ou não, que estão no mundo -, completamente carregado de uma ideologia que deshierarquiza as funções e que destrona os "gênios". Esteticamente, mas também, politicamente, estamos falando de um outro teatro. (LEITE, 2006, p. 3)

A atriz Janaina Leite conduz a uma distinta reflexão também polêmica: os grupos desenvolvem uma realmente nova dramaturgia? Falam de um mesmo ou de um outro teatro? Eugenio Barba em A arte secreta do ator confirma o apontamento de uma nova dramaturgia, um novo teatro:

A distinção entre teatro baseado num texto escrito, ou, em qualquer caso, num texto composto a priori e usado como a matriz da encenação, e teatro cujo 
texto significativo é o texto de representação, simboliza muito bem a diferença entre o teatro "tradicional" e o "novo". (BARBA apud FISCHER, 2005, p. 168)

Em questões de autoria, indiscutivelmente a dramaturgia e o teatro de grupo descobriram e tomaram novos rumos, se ajustando a novas configurações e parâmetros ideológicos de hierarquia e desenvolvendo considerável força criativa. É incontestável que hoje os grupos se libertaram, em maior ou menor grau, da autoridade do texto teatral, no entanto, é pertinente lembrar que não falamos de um teatro de formas e procedimentos fixos e que se constitui exatamente por sua suscetibilidade de modificação. Desse modo, cabe afirmar que a prática e a análise do teatro de grupo demandam constante atenção e atualização - com o risco de enganar a si mesmo com discursos passados.

\section{REFERÊNCIAS}

1 - BARBA, Eugenio e SAVARESE, Nicola. A arte secreta do ator: dicionário de Antropologia teatral. São Paulo/Campinas, Editora Hucitec - Editora da UNICAMP, 1995.

2 - DORT, Bernard. O teatro e sua realidade. São Paulo: Perspectiva, 1977.

3 - FISCHER, Stela R. Processo colaborativo: experiências de companhias teatrais brasileiras dos anos 90. Dissertação de Mestrado da Universidade Estadual de Campinas/SP: 2005.

4 - FORJAZ, Cibele. "Entrevista concedida à Ana Luiza Fortes, André Felipe Costa, Ligia Ferreira e Vinicius Pereira". São Paulo, dezembro de 2007. Entrevista.

5 - LEITE, Janaina. Nós, os “impublicáveis". In: Leite,J.;Sanches,J.;Marques, L.F.;Celestino,P.;Rebouças,R.;Antunes, S.. (Org.). Hysteria/Hygiene - Grupo XIX de Teatro. 01 ed. São Paulo: Grupo XIX de Teatro, 2007, v. 01, p. 3.

6 - MARQUES, Luiz Fernando. "Entrevista concedida à Ana Luiza Fortes, André Felipe Costa, Ligia Ferreira e Vinicius Pereira". São Paulo, dezembro de 2007. Entrevista.

7 - PIRES, Pedro e PESSOA, Zé Ernesto. "Entrevista concedida à Ana Luiza Fortes e Ligia Ferreira". São Paulo, dezembro de 2007. Entrevista.

8 - PAVIS, Patrice. A análise dos espetáculos. São Paulo: Perspectiva, 2003.

9 - PAVIS, Patrice. Dicionário de teatro. São Paulo: Perspectiva, 2005. 
10 - ROUBINE, Jean-Jacques. A linguagem da encenação teatral. Rio de Janeiro: Zahar Editores, 1982.

11 - RYNGAERT, Jean-Pierre. Introdução à análise do teatro. São Paulo: Martins Fontes, 1996.

12 - RYNGAERT, Jean-Pierre. Ler o teatro contemporâneo. São Paulo: Martins Fontes, 1998. 